\title{
EFEITO DA TEMPERATURA E DO pH NO TRATAMENTO DO CALDO DE SORGO SACARINO
}

\author{
Gustavo Henrique Gravatim Costa* \\ Jorge Otávio Missima** \\ Vitor Teixeira*** \\ Miguel Angelo Mutton**** \\ Márcia Justino Rossini Mutton ${ }^{* * * *}$
}

RESUMO: Objetivou-se neste estudo avaliar os efeitos de diferentes faixas de temperaturas e $\mathrm{pH}$ no tratamento do caldo de sorgo sacarino. O delineamento experimental foi em parcelas sub-subdivididas. Os tratamentos principais foram constituídos por diferentes genótipos de sorgo (BRS509, CV568 e BRS511); os tratamentos secundários por diferentes faixas de $\mathrm{pH}(6,0,6,5$ e 7,0); e os terciários pelas faixas de temperatura $65^{\circ} \mathrm{C}, 80^{\circ} \mathrm{C}$ e $100^{\circ} \mathrm{C}$. Avaliaram-se as características químico-tecnológicas dos caldos extraído e clarificado. Observou-se que os genótipos BRS 509 e BRS511 apresentam maiores quantidades de açúcar do que o CV568. O tratamento de caldo a pH 6,0 promove menor remoção de açúcares e não açúcares do caldo. $\mathrm{O}$ aquecimento do caldo a temperaturas inferiores a $100^{\circ} \mathrm{C}$ resulta em flotação do lodo, assim como a remoção do amido presente, em detrimento ao aquecimento a $100^{\circ} \mathrm{C}$, em que se verificou sedimentação do lodo e não remoção de amido, que poderá ser metabolizado pela levedura, quando previamente hidrolisado por enzimas amilolíticas. Conclui-se que o tratamento de caldo a $\mathrm{pH}$ 6,0 e temperatura a $100^{\circ} \mathrm{C}$ é o mais adequado para o sorgo sacarino.

PALAVRAS-CHAVE: Bioenergia; Caleagem simples; Setor sucroenergético; Sorghum bicolor.

\section{TEMPERATURE AND pH EFFECTS ON THE TREATMENT OF SACCHARINE SORGHUM BROTH}

Doutor em Microbiologia Agropecuária pela FCAV/UNESP. Docente na Universidade do Estado de Minas Gerais, Unidade Frutal, Minas Gerais, Brasil. E-mail: ghg_costa@hotmail.com

** Egresso do curso de Tecnologia em Biocombustíveis da FATEC Jaboticabal (SP), Brasil.

*** Programa de Microbiologia Agropecuária, Faculdade de Ciências Agrárias e Veterinárias, Departamento de Tecnologia, Universidade Estadual Paulista/UNESP, Jaboticabal (SP), Brasil.

*** Doutor em Solos e Nutrição de Plantas pela ESALQ/USP. Docente na Faculdade de Ciências Agrárias e Veterinárias, Universidade Estadual "Júlio de Mesquita Filho", Jaboticabal (SP), Brasil.

${ }^{* * * *}$ Programa de Microbiologia Agropecuária, Faculdade de Ciências Agrárias e Veterinárias, Departamento de Tecnologia, Universidade Estadual Paulista/UNESP, Jaboticabal (SP), Brasil. 
ABSTRACT: The effects of different temperatures and $\mathrm{pH}$ on the treatment of saccharine sorghum broth are analyzed. Experimental design comprised sub-subplots and the main treatments consisted of different sorghum genotypes (BRS509, CV568 and BRS511); different secondary treatments at different $\mathrm{pH}(6.0 ; 6.5 ; 7.0)$; tertiary treatments at different temperatures: $65^{\circ} \mathrm{C}, 80^{\circ} \mathrm{C}$ and $100^{\circ} \mathrm{C}$. The chemical and technological characteristics of extracted and clarified broth were assessed. Genotypes BRS 509 and BRS511 had higher amounts of sugar than CV568. Broth at $\mathrm{pH} 6.0$ triggered a lower removal rate of sugars and non-sugars in the broth. The heating of the broth at temperatures lower than $100^{\circ} \mathrm{C}$ caused flotation of slug and the removal of starch to the detriment of heating at $100^{\circ} \mathrm{C}$, when slug sedimentation and non-removal of starch occurred. This may be metabolized by yeast when previously hydrolyzed by amylolytic enzymes. Treatment of broth at $\mathrm{pH}$ 6.0 and at $100^{\circ} \mathrm{C}$ is the most adequate treatment for saccharine sorghum.

KEY WORDS: Bioenergy; Simple liming; Sugar-energy sector; Sorghum bicolor.

\section{INTRODUÇÃO}

O etanol é um dos biocombustíveis mais utilizados no mundo, especialmente no Brasil, onde é empregada, como alternativa, a gasolina em veículos leves. O etanol é produzido a partir da fermentação alcoólica de soluções açucaradas por leveduras do gênero Saccharomyces cerevisiae.

No Brasil, este biocombustível é produzido a partir do processamento industrial da cana-de-açúcar e estima-se que para a safra 2015/2016 serão produzidos aproximadamente 29,2 bilhões de litros (CONAB, 2015). Entretanto, nos últimos anos a demanda por etanol tem crescido, significativamente, impulsionada pelo aumento da frota de veículo "flex fuel". Segundo projeções da Archer Consulting (2014), em 2020, a quantidade de automóveis bicombustíveis irá aumentar de 30 milhões para 40 milhões de carros, resultando em crescimento significativo da demanda.

Neste sentido, faz-se necessária a busca por matérias-primas alternativas que possam complementar a cultura da cana-de-açúcar. Entre estas matérias-primas, destaca-se o sorgo sacarino que apresenta curto ciclo vegetativo (90-120 dias), 
elevada produção em colmos (40-60 t/ha) e em etanol por área (2.500-3.500 L/ha) e todos implementos agrícolas, assim como o parque industrial, são os mesmos utilizados pela cultura da cana-de-açúcar. Deve-se ressaltar ainda que o sorgo pode ser cultivado em áreas de renovação de canaviais, possibilitando o aumento da produção de etanol, sem que ocorra aumento da área agrícola. Outra vantagem desta cultura é o processamento industrial coincidir com o período de entressafra da indústria canavieira, promovendo ampliação do tempo efetivo da fábrica.

Entretanto, estudos referentes ao processamento industrial desta matériaprima são essenciais para a obtenção de maiores rendimentos em etanol produzidos. Neste contexto, deve-se avaliar detalhadamente o processo de tratamento do caldo do sorgo, que objetiva remover compostos tóxicos para a levedura em fermentação, tais como terra, bagacilhos, compostos fenólicos, ácidos, entre outros.

Atualmente, o tratamento utilizado pelas usinas sucroenergéticas é denominado caleagem simples, que consiste na adição de hidróxido de cálcio para a elevação do pH do caldo de cana para faixa de 6,0-7,0, e aquecimento do caldo a $100-105^{\circ} \mathrm{C}$, a fim de possibilitar a formação e a precipitação de flocos, que ao sedimentarem, adsorvem e arrastam impurezas. Posteriormente, este material precipitado, denominado lodo, é separado em um decantador. Cabe destacar que os flocos são formados por meio da reação entre o fósforo presente no caldo e o cálcio adicionado, que resulta em um composto insolúvel denominado fosfato de cálcio (DOHERTY, 2011).

Entretanto, estes processos são válidos quando se considera o tratamento do caldo de cana, não havendo informações específicas disponíveis na literatura, quando se processa o caldo de sorgo sacarino. Neste contexto, o objetivo do trabalho foi avaliar os reflexos de diferentes faixas de $\mathrm{pH}$ e temperatura no tratamento do caldo de sorgo sacarino.

\section{MATERIAL E MÉTODOS}

O experimento foi instalado na área experimental do Departamento de Produção Vegetal e conduzido no Laboratório de Tecnologia do Açúcar e do Álcool da FCAV/Unesp - campus Jaboticabal, na safra 2012/2013, sendo o plantio realizado 
em 03 de janeiro de 2013.

O delineamento experimental utilizado foi o em blocos casualizados com parcelas sub-subdivididas. O tratamento principal foi constituído por caldos provenientes de três genótipos de sorgo sacarino (BRS509, CV568 e BRS511); tratamento secundário representado pela clarificação do caldo em três diferentes faixas de pHs $(6,0,6,5,7,0)$; e o tratamento terciário o aquecimento do caldo caleado em três diferentes temperaturas $\left(65,80\right.$ e $\left.100^{\circ} \mathrm{C}\right)$. Foram empregadas três repetições para as análises químico-tecnológicas.

Os genótipos de sorgo sacarino foram colhidos em seu estágio de maturação (grãos duros), aos 110 dias após a semeadura (22/04/2013). Foi realizada a remoção das panículas dos colmos colhidos. O caldo foi extraído em moenda e submetido ao processo de tratamento de caldo por caleagem simples. Inicialmente elevou-se o $\mathrm{pH}$ do caldo até as faixas estipuladas, pela adição de $\mathrm{CaOH}_{2} 6^{\circ}$ Bé. A seguir o caldo caleado foi aquecido até as temperaturas 65,80 e $100^{\circ} \mathrm{C}$, que foram controladas por meio de um termômetro, sendo posteriormente, dispostos (o caldo?) em sistema de decantação aquecido por lâmpadas. Nesta etapa, adicionaram-se 2,0 ppm de polieletrólito Magnafloc por litro de caldo. Após 20 minutos de repouso, o caldo foi separado do lodo através de filtração em papel de filtro qualitativo.

O caldo extraído foi caracterizado quanto ao ${ }^{\circ}$ Brix, Pol, Pureza, $\mathrm{pH}$, Açúcares Redutores (AR), Açúcares Redutores Totais (ART), amido, ácidos totais (AT), fosfatos totais (FT), cinzas solúveis (CS), turbidez (ICUMSA, 2013) e compostos fenólicos totais (CFT) (FOLIN; CIOCALTEU, 1927).

Durante o processo de clarificação, avaliou-se a velocidade de sedimentação $(\mathrm{cm} / \mathrm{min})$ e a porcentagem de lodo precipitado no decantador (ICUMSA, 2013).

Os resultados foram submetidos à análise de variância pelo teste $\mathrm{F}$, e as médias avaliadas segundo teste de Tukey (5\%).

\section{RESULTADO E DISCUSSÃO}

Os genótipos BRS509 e BRS511 apresentaram $17^{\circ}$ Brix, 1,5\% de AR, 563 e $312 \mathrm{mg} / \mathrm{L}$ de CFT respectivamente. O genótipo CV568 apresentou $12,5^{\circ} \mathrm{Brix}$, 3,18\% de AR, e 271mg/L de CFT. Considerando-se os demais parâmetros avaliados, verificou-se que os genótipos apresentaram Pol próximo a 9\%, Pureza de 56\%, ART 
de $12 \%$, pH de 4,7, amido entre 1100 e $1.700 \mathrm{mg} / \mathrm{L}$, AT de 1,60g/L, FT de $300 \mathrm{mg} / \mathrm{L}$, CS de $0,99 \%$ e turbidez entre 1,082 e 1,318 NTU, parâmetros que conferiam as matérias-primas o estágio ideal de maturação.

Após a caracterização da matéria-prima, o segundo passo foi realizar a clarificação do caldo. Neste processo, avaliou-se a velocidade de sedimentação das impurezas presentes no caldo (Tabela 1) e o volume destas impurezas ocupado no fundo do decantador (volume de lodo).

Tabela 1. Valores médios obtidos para velocidade de sedimentação e Brix do caldo clarificado de três genótipos de sorgo sacarino em três faixas de $\mathrm{pH}$ e temperaturas. Jaboticabal/SP. Safra 2012/2013

\begin{tabular}{|c|c|c|c|}
\hline \multirow{2}{*}{\multicolumn{2}{|c|}{ Treatments }} & Velocidade Sedimentação & Brix \\
\hline & & $\mathrm{cm} / \mathrm{min}$ & $\%$ \\
\hline \multirow{3}{*}{ Genótipos } & BRS509 & $4,41 \mathrm{a}$ & $17,6 a$ \\
\hline & CV568 & $4,82 \mathrm{a}$ & $13,7 \mathrm{a}$ \\
\hline & BRS511 & $4,48 \mathrm{a}$ & $16,5 a$ \\
\hline \multirow{6}{*}{ pH } & Teste $\mathbf{F}$ & $2.18 \mathrm{~ns}$ & $5,00 \mathrm{~ns}$ \\
\hline & DMS & 0.73 & 4,55 \\
\hline & $\mathrm{CV}$ & 16.70 & 29,62 \\
\hline & 6.0 & $4,78 \mathrm{a}$ & $16,3 \mathrm{a}$ \\
\hline & 6.5 & $4,64 a b$ & $15,9 \mathrm{ab}$ \\
\hline & 7.0 & $4,28 \mathrm{~b}$ & $15,6 \mathrm{~b}$ \\
\hline \multirow{6}{*}{ Temp. } & Teste $\mathbf{F}$ & $4.52^{*}$ & $3,71^{*}$ \\
\hline & DMS & 0.45 & 0,71 \\
\hline & $\mathrm{CV}$ & 13.71 & 6,13 \\
\hline & $65^{\circ} \mathrm{C}$ & $4,77 \mathrm{a}$ & $15,6 \mathrm{c}$ \\
\hline & $80^{\circ} \mathrm{C}$ & $4,68 \mathrm{a}$ & $15,9 \mathrm{~b}$ \\
\hline & $100{ }^{\circ} \mathrm{C}$ & $4,25 \mathrm{~b}$ & $16,2 \mathrm{a}$ \\
\hline & Teste $\mathbf{F}$ & $17.29 * *$ & $35,25 * *$ \\
\hline & DMS & 0.23 & 0,17 \\
\hline & $\mathrm{CV}$ & 7.71 & 1,65 \\
\hline \multicolumn{2}{|c|}{ Inter $\mathbf{G} \times \mathrm{pH}$} & $0.30 \mathrm{~ns}$ & $0,08 \mathrm{~ns}$ \\
\hline \multicolumn{2}{|c|}{ Inter $G \times$ Temp } & $1.69 \mathrm{~ns}$ & $0,34 \mathrm{~ns}$ \\
\hline \multicolumn{2}{|c|}{ Inter $\mathrm{pH} \times$ Temp } & $0.06 \mathrm{~ns}$ & $0,27 \mathrm{~ns}$ \\
\hline \multicolumn{2}{|c|}{ Inter $\mathbf{G} \times \mathrm{pH} \times \mathrm{Temp}$} & $0.92 \mathrm{~ns}$ & $1,89 \mathrm{~ns}$ \\
\hline
\end{tabular}


na. DMS = Desvio Mínimo Significativo. CV = Coeficiente de Variação.

Avaliando-se a velocidade de sedimentação do caldo extraído de três genótipos, observaram-se valores entre 4,41 e $4,82 \mathrm{~cm} / \mathrm{min}$. Tais resultados são superiores aos indicados por Costa et al. (2015), que, trabalhando com as mesmas condições de clarificação, determinaram valores determinados próximos a $2,89 \mathrm{~cm} /$ min, quando processou o genótipo CVSW80007. Com base nessas informações, verificamos que o uso de sorgo sacarino como matéria-prima não afeta as condições operacionais do tratamento de caldo.

Estudando a clarificação do caldo de sorgo sacarino em diferentes faixas de $\mathrm{pH}$, verificou-se que o $\mathrm{pH} \mathrm{7,0} \mathrm{resultou} \mathrm{em} \mathrm{velocidade} \mathrm{de} \mathrm{sedimentação} \mathrm{inferior} \mathrm{às}$ demais. Este fato pode ser associado à maior formação de fosfato de cálcio, resultante da maior adição de leite de cal para atingir este valor.

Analisando-se os resultados obtidos para a clarificação do caldo em diferentes temperaturas, observou-se que elevadas temperaturas promovem decréscimo da velocidade de sedimentação. Tal fato pode estar relacionado à desnaturação de proteínas nesta faixa de temperatura, promovendo maior carga de lodo a ser sedimentado (DOHERTY, 2011). Deve-se ressaltar que o aquecimento a 65 e $80^{\circ} \mathrm{C}$ promoveu flotação do lodo formado (Figura 1), provavelmente pelo fato de ocorrer uma remoção incompleta de gases presentes no caldo, os quais reagem com os flocos menos densos, carregando-os para a parte superior do decantador (ALBUQUERQUE, 2011). Nestes casos é necessária a substituição dos decantadores das fábricas, uma vez que estes separam o lodo do caldo clarificado por sedimentação. Nestas condições de processo é necessária a implementação de um flotador, para retirar o lodo no topo do equipamento. 


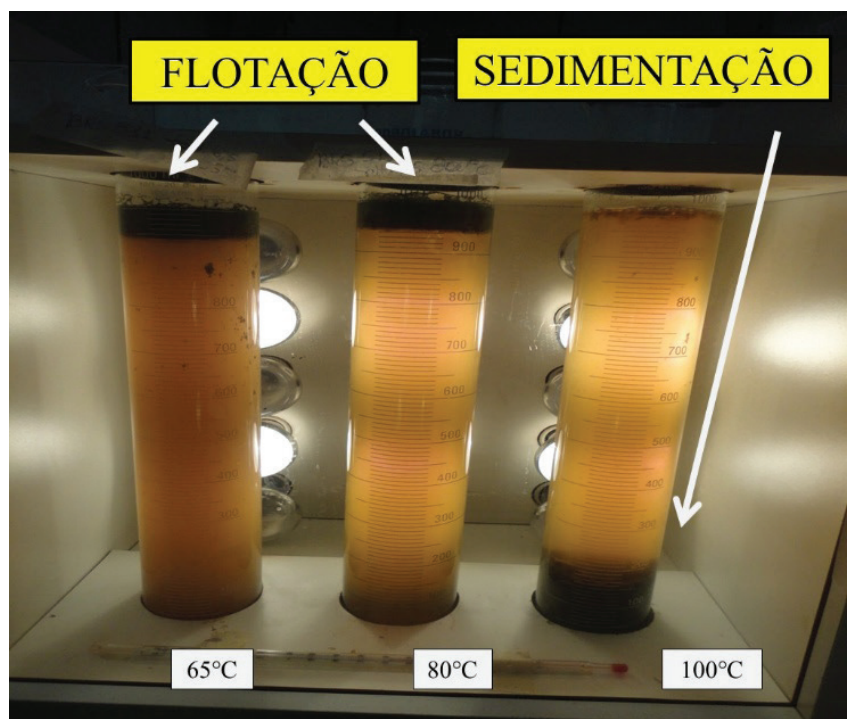

Figura 1. Imagem representativa do tratamento de caldo de sorgo sacarino em três faixas de temperaturas após 20 minutos em repouso em decantador aquecido por lâmpadas. Jaboticabal-SP. Safra $2012 / 2013$

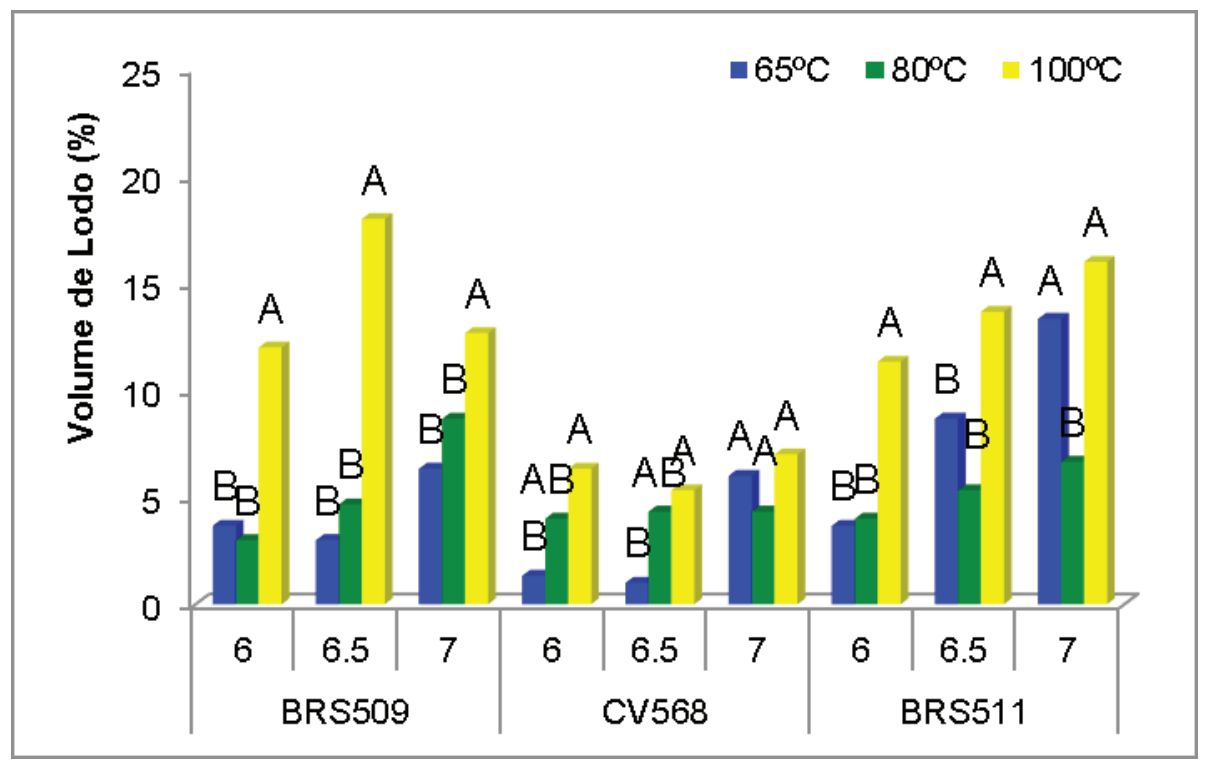

Figura 2. Representação gráfica do desdobramento dos resultados obtidos para volume de lodo formado ao longo do processo de clarificação do caldo extraído de três genótipos de sorgo sacarino em diferentes faixas de $\mathrm{pH}$ e temperaturas. Jaboticabal-SP. Safra 2012/2013 
Comparando-se os valores obtidos para volume de lodo formado na clarificação do caldo extraído dos três genótipos de sorgo sacarino (Figura 2), foram verificadas menores médias para o genótipo CV568, em relação aos demais. Em relação ao volume de lodo que forma em diferentes faixas de $\mathrm{pH}$, observou-se maiores volumes de lodo para $\mathrm{pH}$ 7,0. Assim como a velocidade de sedimentação, o volume de lodo pode estar relacionado com as quantidades de fosfatos de cálcio formados, que nesta faixa de pH é maior (COSTA et al., 2015).

Avaliando-se o volume de lodo formado no tratamento do caldo de sorgo sacarino em diferentes faixas de temperaturas, observaram-se maiores quantidades deste composto para a clarificação realizada a $100^{\circ} \mathrm{C}$. Os resultados obtidos para as faixas de 65 e $80^{\circ} \mathrm{C}$ indicaram valores duas vezes menores, em relação à máxima temperatura estudada. A partir de tais informações, pode-se constatar que altas temperaturas na clarificação do caldo extraído acarretam maiores volumes de lodo formado, provavelmente, por possibilitar a precipitação de maiores quantidades de impurezas, além de remover gases contidos no caldo.

Após o tratamento do caldo, o próximo passo foi determinar a qualidade do caldo clarificado, quantificando-se o Brix, pH, AT, CFT, CS, amido e turbidez.

Avaliando-se o Brix do caldo clarificado dos três genótipos de sorgo sacarino (Tabela 2), observou-se que os mesmos não apresentaram diferenças significativas. Deve-se destacar que o tratamento do caldo de sorgo sacarino não removeu sólidos solúveis do caldo clarificado, comparando-se ao caldo original. Este comportamento foi similar ao apresentado por Costa et al. (2015). Este fato é interessante, pois assemelha-se à dinâmica do tratamento do caldo de cana, o qual também não há remoção de Brix. Entretanto, verificou-se que a utilização de $\mathrm{pH}$ 7,0 promoveu maiores remoções de sólidos solúveis no caldo clarificado. Este comportamento é resultado da maior adição de cálcio no caldo nesta faixa de $\mathrm{pH}$, a qual promove maior remoção de compostos quantificados no Brix, tais como fosfatos e ácidos orgânicos (ANDRZEJEWSKI et al., 2013). 
Tabela 2. Valores médios obtidos para ácidos totais (AT), pH, compostos fenólicos totais (CFT) e cinzas solúveis (CS) do caldo clarificado de três genótipos de sorgo sacarino em três faixas de pH e temperaturas. Jaboticabal/SP. Safra 2012/2013

\begin{tabular}{|c|c|c|c|c|c|}
\hline \multirow{2}{*}{\multicolumn{2}{|c|}{ Treatments }} & AT & pH & CFT & CS \\
\hline & & $\mathrm{gH}_{2} \mathrm{SO}_{4} / \mathrm{L}$ & & $\mathrm{mg} / \mathrm{Kg}$ & $\%$ \\
\hline \multirow{6}{*}{ 总 } & BRS509 & $0,72 \mathrm{a}$ & $6,0 \mathrm{a}$ & $178 \mathrm{ab}$ & $1,04 a$ \\
\hline & CV568 & $0,53 \mathrm{a}$ & $6,1 \mathrm{a}$ & $168 \mathrm{~b}$ & $1,00 \mathrm{a}$ \\
\hline & BRS511 & $0,63 \mathrm{a}$ & $6,0 \mathrm{a}$ & 211a & $0,99 \mathrm{a}$ \\
\hline & Teste F & $1,08 \mathrm{~ns}$ & $1,08 \mathrm{~ns}$ & $0,16 \mathrm{~ns}$ & $0,12 \mathrm{~ns}$ \\
\hline & DMS & 0,43 & 0,43 & 0,55 & 0,38 \\
\hline & $\mathrm{CV}$ & 71.55 & 71,55 & 9,46 & 3,79 \\
\hline \multirow{6}{*}{ 플 } & 6.0 & $0,74 a$ & $5,7 \mathrm{c}$ & $188 \mathrm{a}$ & $1,04 a$ \\
\hline & 6.5 & $0,60 \mathrm{~b}$ & $6,0 \mathrm{~b}$ & $183 a$ & $1,00 \mathrm{a}$ \\
\hline & 7.0 & $0,55 \mathrm{~b}$ & $6,3 \mathrm{a}$ & $185 a$ & $1,00 \mathrm{a}$ \\
\hline & Teste F & $25.54 * *$ & $25,54 * *$ & $221,17^{* *}$ & $1,19 \mathrm{~ns}$ \\
\hline & DMS & 0.07 & 0,07 & 0,06 & 0,07 \\
\hline & CV & 15.90 & 15,90 & 1,51 & 9,63 \\
\hline \multirow{3}{*}{ 宅 } & $65^{\circ} \mathrm{C}$ & $0,62 \mathrm{a}$ & $6,1 \mathrm{a}$ & $190 \mathrm{a}$ & $0,99 \mathrm{~b}$ \\
\hline & $80^{\circ} \mathrm{C}$ & $0,63 a$ & $6,0 \mathrm{~b}$ & 186a & $1,01 \mathrm{ab}$ \\
\hline & $100^{\circ} \mathrm{C}$ & $0,64 a$ & $5,9 \mathrm{c}$ & $181 \mathrm{a}$ & $1,04 a$ \\
\hline & Teste F & $0.45 \mathrm{~ns}$ & $0,45 \mathrm{~ns}$ & $28,61 * *$ & $3,53^{*}$ \\
\hline & DMS & 0.04 & 0,04 & 0,05 & 0,04 \\
\hline & CV & 11.53 & 11,53 & 1,31 & 6,44 \\
\hline & Inter G x pH & $1.69 \mathrm{~ns}$ & $1,69 \mathrm{~ns}$ & $1,84 \mathrm{~ns}$ & $0,33 \mathrm{~ns}$ \\
\hline \multicolumn{2}{|c|}{ Inter G x Temp } & $1.74 \mathrm{~ns}$ & $1,74 \mathrm{~ns}$ & $1,02 \mathrm{~ns}$ & $0,26 \mathrm{~ns}$ \\
\hline \multicolumn{2}{|c|}{ Inter $\mathbf{p H} \mathbf{x}$ Temp } & $0.97 \mathrm{~ns}$ & $0,97 \mathrm{~ns}$ & $0,86 \mathrm{~ns}$ & $0,80 \mathrm{~ns}$ \\
\hline \multicolumn{2}{|c|}{ Inter $\mathbf{G} \times \mathrm{pH} \times$ Temp } & $1.33 \mathrm{~ns}$ & $1,33 \mathrm{~ns}$ & $1,13 \mathrm{n}$ & $1,27 \mathrm{~ns}$ \\
\hline
\end{tabular}

** significativo ao nível de $1 \%$ de probabilidade $(\mathrm{p}<0,01) ; *$ significativo ao nível de $5 \%$ de probabilidade $(\mathrm{p}<0,05)$ e ns não significativo $(\mathrm{p}>0,05)$. Letras minúsculas comparam valores na coluna. DMS = Desvio Mínimo Significativo. CV = Coeficiente de Variação. 
Considerando-se os valores apresentados para Brix do caldo clarificado em diferentes faixas de temperaturas, observou-se que o aquecimento promovido na faixa de $100^{\circ} \mathrm{C}$ resultou em maiores valores médios. Os resultados apresentados foram correspondentes aos relatados por Andrzejewski et al. (2013), que avaliando a clarificação do caldo de sorgo sacarino em diferentes temperaturas, observaram pequenos acréscimos nos valores obtidos para caldo clarificado conforme a temperatura que se aproximou de $100^{\circ} \mathrm{C}$. Este comportamento deve estar relacionado à ebulição provocada pelo aquecimento sob temperaturas elevadas, que provocam a evaporação da água, concentrando os sólidos solúveis no caldo.

Avaliando-se os teores de amido do caldo clarificado de sorgo sacarino, observou-se que, de modo geral, os genótipos BRS509 e BRS511 apresentaram maiores níveis de amido comparado ao CV568 (Figura 3). Neste sentido, verificouse também quanto mais elevado o $\mathrm{pH}$, maior foi a remoção desta biomolécula. Fato também constatado por Andrzejewski et al. (2013) que, realizando a clarificação do caldo de sorgo sacarino, constataram decréscimos nos valores de amido em faixa de $\mathrm{pH}$ próximo a 7,0. Este comportamento é resultante da adsorção de partículas de amido, ou mesmo a sua remoção mecânica por meio de flocos de fosfatos de cálcio que, quando sedimentam, arrastam esta molécula para a parte inferior do decantador. Deve-se ressaltar que em maiores faixas de pH há maior formação de fosfatos de cálcio.

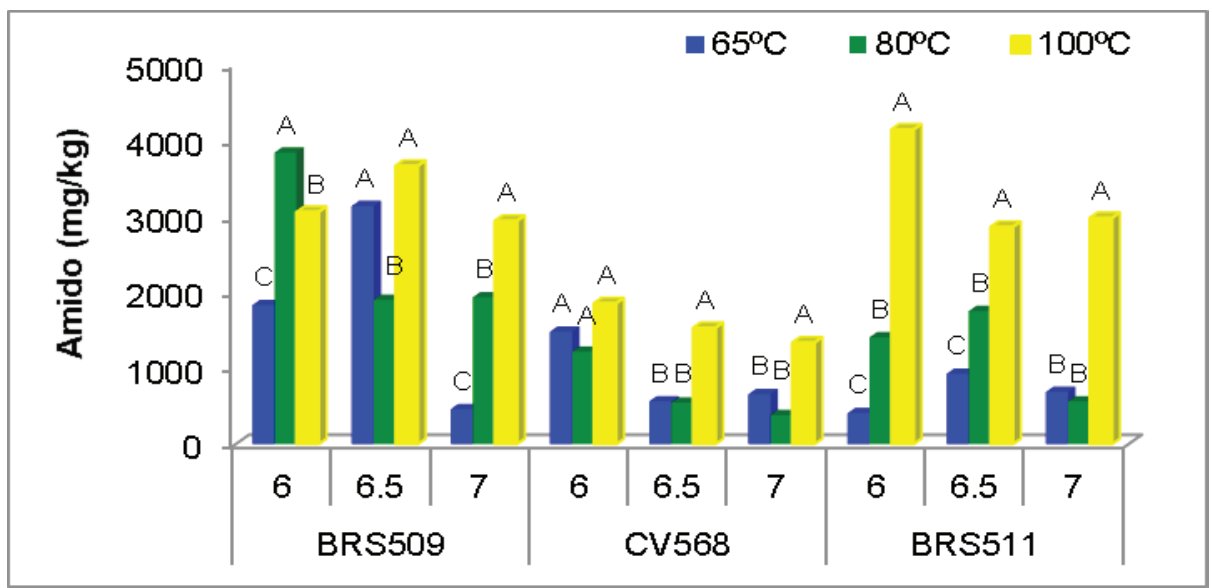

Figura 3. Representação gráfica do desdobramento dos resultados obtidos para amido do caldo clarificado de três genotipos de sorgo sacarino em diferentes faixas de $\mathrm{pH}$ e temperaturas.

Jaboticabal-SP. Safra 2012/2013 
Considerando-se os teores de amido do caldo clarificado de sorgo sacarino a partir de três diferentes estágios de aquecimento, constatou-se que ocorreram maiores remoções deste polissacarídeo para temperatura de $65^{\circ} \mathrm{C}$. Os resultados obtidos foram semelhantes aos encontrados por Andrzejewski et al. (2013) que observaram menores quantidades desta biomolécula no caldo clarificado em temperaturas de clarificação inferiores a $100^{\circ} \mathrm{C}$. Desta maneira, verifica-se que a remoção do amido, durante o processo de clarificação, se deve, principalmente, ao fato deste composto ser solubilizado a temperaturas superiores a $67^{\circ} \mathrm{C}$ (ANDRZEJEWSKI et al., 2013).

Avaliando-se as concentrações de AT do caldo clarificado de três genótipos de sorgo sacarino (Figura 4A), observaram-se valores semelhantes para os genótipos. Entretanto, deve-se ressaltar que o tratamento do caldo por defecação simples promoveu elevada redução de tais biomoléculas. 


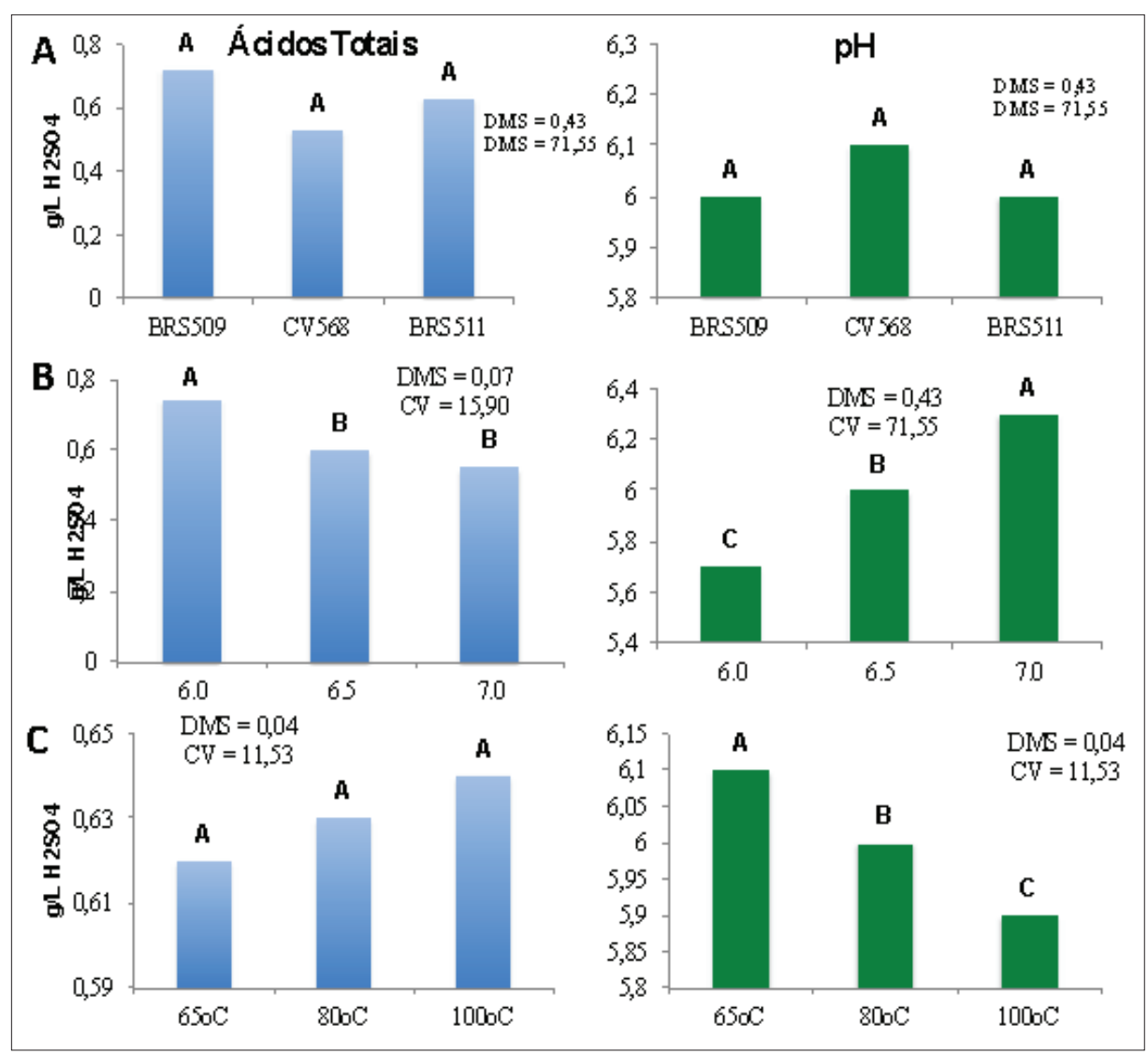

Figura 4. Representação gráfica das médias obtidas para Acidez Total e pH do caldo clarificado de três genótipos (A), três faixas de pH (B) e três faixas de temperatura (C). Jaboticabal-SP. Safra 2012/2013

Considerando-se os resultados obtidos para AT do caldo clarificado em $\mathrm{pH}$ 6,0, 6,5 e 7,0 (Figura 4B), verificou-se que quanto maior o $\mathrm{pH}$ do caldo dosado, maior foi a remoção destes elementos. Este fato deve estar associado a maior formação de fosfatos de cálcio conforme houve aumento da adição de leite de cal, uma vez que tais compostos ao precipitarem no decantador adsorvem ácidos (DOHERTY, 2011). Pode-se destacar ainda que a utilização de diferentes temperaturas não refletiu na quantidade de AT presentes no caldo (Figura 4C).

Caracterizando-se o $\mathrm{pH}$ do caldo clarificado dos três genótipos estudados (Figura 4A), verificaram-se valores semelhantes entre as matérias-primas. Deve- 
se destacar ainda que os resultados obtidos para $\mathrm{pH}$ do caldo clarificado foram superiores aos do extraído, uma vez que a realização da caleagem do caldo, pela adição de leite de cal, promove a elevação do $\mathrm{pH}$.

Analisando-se as três faixas de temperaturas (Figura 4C) utilizadas na clarificação do caldo extraído sobre os valores de $\mathrm{pH}$, observou-se que quanto maior foi o aquecimento do caldo caleado, menor foi o valor do $\mathrm{pH}$ do caldo clarificado. Considerando que o aquecimento a $100^{\circ} \mathrm{C}$ tem por objetivo acelerar as reações entre o leite de cal e os fosfatos presentes no caldo (HONIG, 1969), e pode-se inferir que baixas temperaturas não promoveram a formação total de fosfatos de cálcio.

Estudando-se as quantidades de CFT do caldo clarificado de três genótipos de sorgo sacarino (Figura 5A), observou-se que o genótipo BRS511 apresentou maiores valores desses compostos no caldo clarificado, em relação aos demais. Entretanto, deve-se destacar que houve diminuição destas biomoléculas após o processo de clarificação do caldo extraído para todos os genótipos avaliados. Este fato é interessante, uma vez que Honig (1969) aponta que o sistema de clarificação por caleagem simples não remove CFT. Entretanto, Costa et al. (2015) também verificaram reduções de CFT quando realizaram clarificação do caldo de sorgo sacarino. A redução destas biomoléculas é significante, uma vez que estas são inibidores do metabolismo da levedura durante o processo fermentativo, resultando em significava redução do teor alcoólico do vinho, assim como alterações na composição do destilado. Deve-se destacar que estes efeitos ocorrem quando o caldo extraído apresenta CFT superiores a $400 \mathrm{mg} / \mathrm{L}$ (RAVANELLI et al., 2011). 


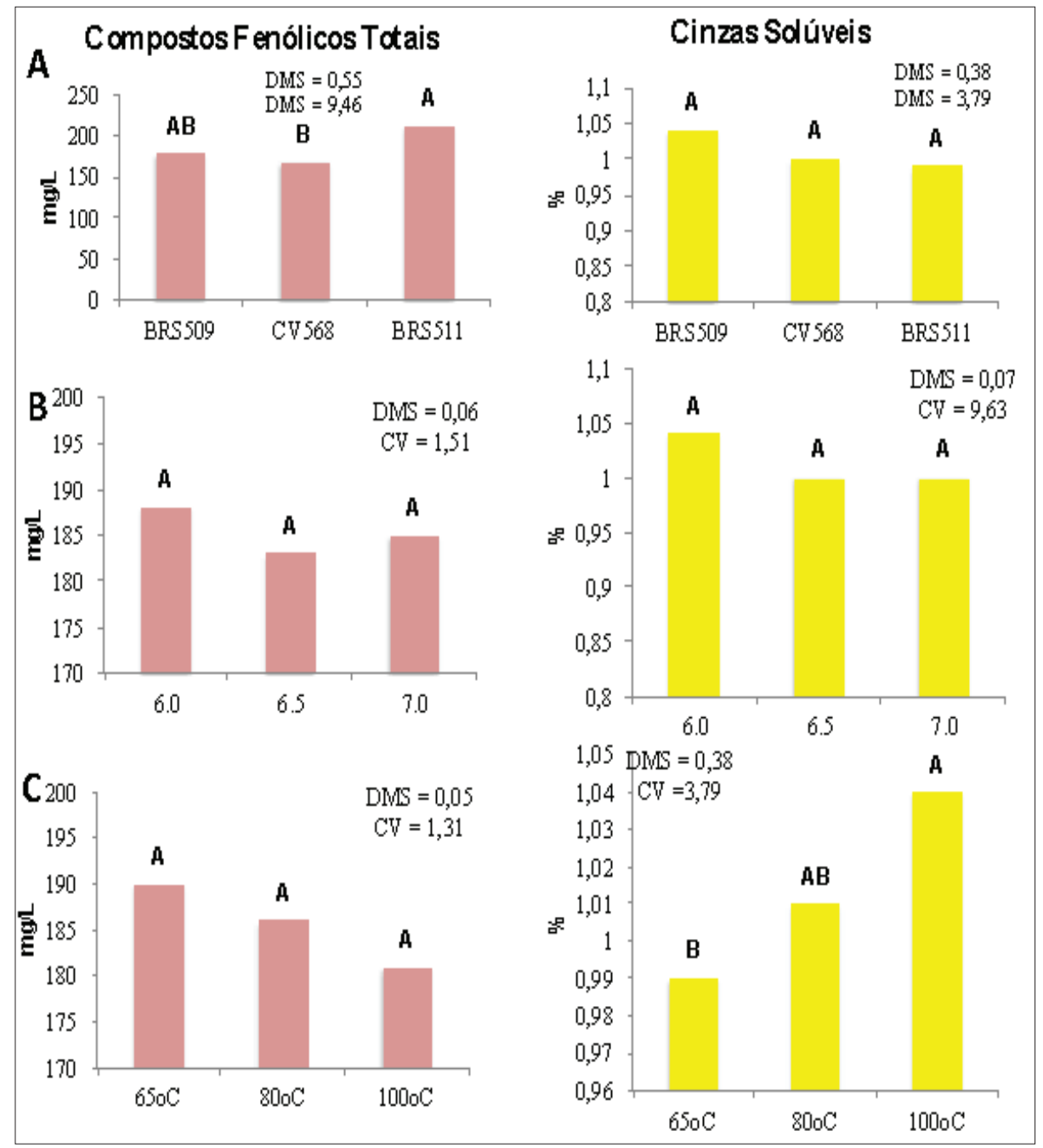

Figura 5. Representação gráfica das médias obtidas para Compostos Fenólicos Totais e Cinzas Solúveis do caldo clarificado de três genótipos (A), três faixas de $\mathrm{pH}$ (B) e três faixas de temperatura (C). Jaboticabal-SP. Safra 2012/2013

Com relação à quantidade de compostos fenólicos no caldo clarificado em três faixas de $\mathrm{pH}$ (Figura 5B) e temperatura (Figura 5C), não foram observadas diferenças significativas entre os tratamentos. De acordo com Simpson (1996), a remoção de alguns compostos fenólicos do caldo de cana, somente pode ser conseguida pela adição de grandes quantidades de cal. Neste estudo, a clarificação 
em pH 6,0 foi suficiente para remover CFT. Este efeito pode estar associado à classe de compostos fenólicos presentes no caldo de sorgo sacarino, que são diferentes ao da cana. Entretanto, esta avaliação não foi objeto de investigação neste estudo, sendo que futuras pesquisas são necessárias para determinar estas diferenças. Assim, pode-se inferir que o mínimo tratamento do caldo aplicado pela unidade industrial pode resultar em benefícios diretos para o processo de fermentação.

Quantificando-se as CS do caldo clarificado de três genótipos de sorgo sacarino (Figura 5A), observaram-se valores da ordem de 1,01\%. Neste sentido, pode-se verificar ainda que o aumento do $\mathrm{pH}$ na clarificação do caldo não afetou este parâmetro. Entretanto, na medida em que se aumentou o aquecimento, elevaram-se os teores de cinzas no caldo. Este fenômeno pode ser decorrente da perda de água por evaporação em elevadas temperaturas, resultando na concentração destes íons, fenômeno também observado para o Brix.

Analisando-se a turbidez do caldo clarificado dos três genótipos de sorgo sacarino, em diferentes faixas de $\mathrm{pH}$ e temperatura, verificou-se comportamento diferente entre eles (Figura 6). De modo geral, observou-se que a clarificação do genótipo CV568 apresentou maior turbidez em relação aos demais.

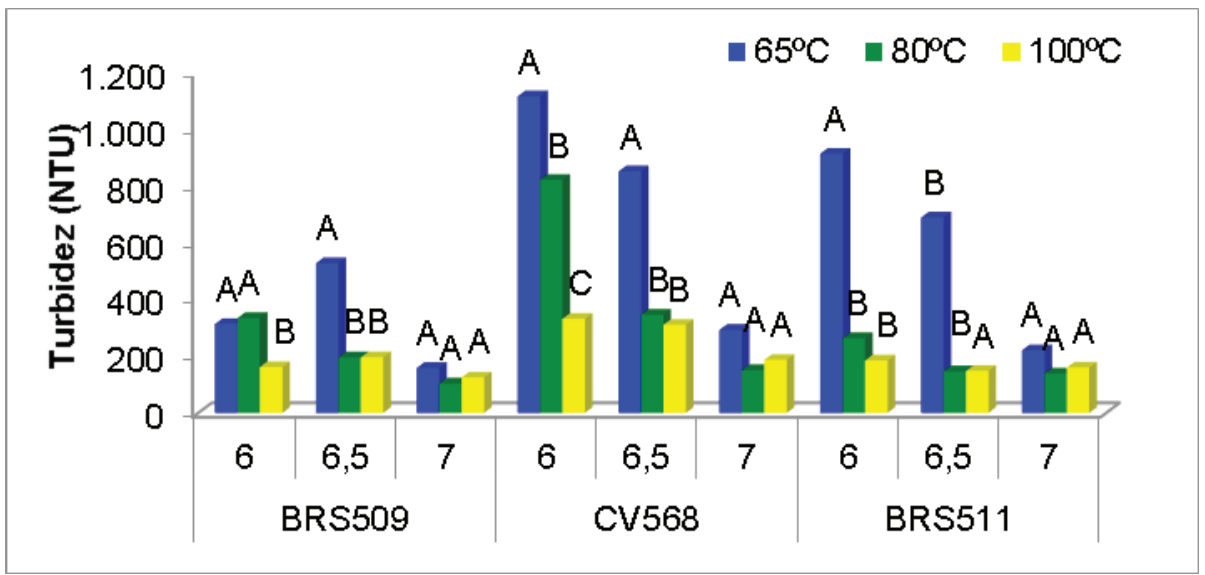

Figura 6. Representação gráfica do desdobramento dos resultados obtidos para turbidez do caldo clarificado de três genótipos de sorgo sacarino em diferentes faixas de $\mathrm{pH}$ e temperaturas. Jaboticabal-SP. Safra 2012/2013 
Considerando-se as diferentes faixas de $\mathrm{pH}$ estudadas, houve redução da turbidez conforme aumento do $\mathrm{pH}$. Neste sentido, também foi verificado que o aumento de temperatura resultou em decréscimo deste parâmetro.

Em relação ao comportamento da turbidez do caldo clarificado em diferentes faixas de $\mathrm{pH}$, pode-se inferir que a maior adição de leite de cal promoveu a maior formação de fosfatos de cálcio, os quais ao precipitarem removeram maiores quantidades de compostos dispersores de luz. Tais resultados também foram relatados por Andrzejewski et al. (2013), que constataram redução da turbidez do caldo clarificado de sorgo sacarino conforme aumento de $\mathrm{pH}$.

A redução da turbidez do caldo clarificado a $100^{\circ} \mathrm{C}$ é consequência da maior remoção de proteínas, assim como da eliminação de gases, que podem promover a dispersão de partículas no decantador (HONIG, 1969). Apesar da redução da turbidez conforme aumento da temperatura, as proteínas são importantes para as leveduras durante o processo fermentativo, uma vez que elas são fontes de nitrogênio utilizadas para a síntese de DNA, parede celular e enzimas (WALKER, 1998).

\section{CONSIDERAÇÕES FINAIS}

O tratamento do caldo de sorgo sacarino, utilizando-se $\mathrm{pH}$ 7,0 e temperatura de $100^{\circ} \mathrm{C}$, é mais eficiente para se obter maior eficiência de processo e caldo clarificado de melhor qualidade.

O processamento de diferentes genótipos de sorgo sacarino não afeta o processo de tratamento do caldo.

\section{REFERÊNCIAS}

ALBUQUERQUE, F. M. Processo de Fabricação de Açúcar. 3. ed. Recife: UFPE, 2011. p. 447.

ANDRZEJEWSKI, B.; EGGLESTON, G.; LINGLE, S.; POWELL, R. Development of a sweet sorghum juice clarification method in the manufacture of industrial feedstocks for value-added fermentation products. Industrial Crops and Products, n. 44, p. 
77-87, 2013.

ARCHER CONSUlTING. Perspectivas dos mercados de açúcar e etanol Perspectivas para o agribusiness 2014/2015. Disponível em: <http://www. bmfbovespa.com.br/pt-br/download/Arquivo7.pdf > . Acesso em: 08 fev. 2016.

CONAB. Companhia Nacional de Abastecimento. $3^{\circ}$ Acompanhamento da safra brasileira. Disponível em: <http://conab.gov.br/OlalaCMS/uploads/ arquivos/15_12_17_09_03_29_boletim_cana_portugues_-_3o_lev_-_15-16. pdf $>$. Acesso em: 22 fev. 2016.

COSTA, G. H. G.; FREITA, C. M.; FREITA, L. A.; MUTTON; M. J. R. Effects of Different Coagulants on Sweet Sorghum Juice Clarification. Sugar Tech, v.17, n.2, p. 210-213, 2014.

DOHERTY, W. O. S. Improved Sugar Cane Juice Clarification by Understanding Calcium Oxide-Phosphate-Sucrose Systems. Journal of Agricultural and Food Chemisty, v. 59, p. 1829-1836, 2011.

FOLIN, O.; CIOCALTEAU, V. On tyrosine and tryptophane determinations in proteins. The journal of biological chemistry, v. 73, n. 2, p. 627-50, 1927.

HONIG, P. Princípios de Tecnologia Azucarera. Mexico: Companhia Continental, 1969.

ICUMSA - International Comission for Uniform Methods of Sugar Analysis. Methods Book. Berlin: Bartens, 2013.

RAVANELI, G. C.; GARCIA, D. B.; MADALENO, L. L.; MUTTON, M. A.; STUPIELLO, J. P.; MUTTON, M. J. R. 2011. Spittlebug impacts on sugarcane quality and ethanol production. Pesquisa Agropecuária Brasileira, v. 46, n. 2, p. 120-129, 2011.

SIMPSON, R. The chemistry of clarification. Proceedings of the South African sugar technologists' association. Durban, p. 267-271, 1996.

WALKER, G. M. Yeast Physiology and Biotechnology. Hoboken: Wiley, 1998.

Recebido em: 2016-02-22

Aceito em: 2017-03-01 
